\title{
Psychoses, ethnicity and socio-economic status
}

\author{
J. B. Kirkbride, D. Barker, F. Cowden, R. Stamps, M. Yang, P. B. Jones and J. W. Coid
}

\section{Background}

Consistent observation of raised rates of psychoses among Black and minority ethnic (BME) groups may possibly be explained by their lower socio-economic status.

\section{Aims \\ To test whether risk for psychoses remained elevated in BME populations compared with the White British, after adjustment for age, gender and current socio-economic status.}

\section{Method}

Population-based study of first-episode DSM-IV psychotic disorders, in individuals aged 18-64 years, in East London over 2 years.

\section{Results}

All BME groups had elevated rates of a psychotic disorder after adjustment for age, gender and socio-economic status For schizophrenia, risk was elevated for people of Black
Caribbean (incidence rate ratios (IRR) $=3.1,95 \% \mathrm{Cl} 2.1-4.5$ ) and Black African (IRR=2.6, 95\% $\mathrm{Cl} 1.8-3.8$ ) origin, and for Pakistani (IRR=3.1, 95\% Cl 1.2-8.1) and Bangladeshi (IRR=2.3, $95 \% \mathrm{Cl} 1.1-4.7)$ women. Mixed White and Black Caribbean (IRR=7.7, 95\% Cl 3.2-18.8) and White Other (IRR=2.1, 95\% Cl 1.2-3.8) groups had elevated rates of affective psychoses (and other non-affective psychoses).

\section{Conclusions}

Elevated rates of psychoses in BME groups could not be explained by socio-economic status, even though current socio-economic status may have overestimated the effect of this confounder given potential misclassification as a result of downward social drift in the prodromal phase of psychosis. Our findings extended to all BME groups and psychotic disorders, though heterogeneity remains.

\section{Declaration of interest}

None. Funding detailed in Acknowledgements.
Variance in incidence is a fundamental prerequisite to understanding the aetiology of psychosis. ${ }^{1}$ Raised rates of psychoses have been reported in immigrant populations since Ödegaard's ${ }^{2}$ study of Norwegian immigrants to New York in the 1930s, and a recent meta-analysis of 40 studies found that the incidence of schizophrenia associated with immigrant status was, on average, nearly threefold greater than for native populations. ${ }^{3}$

In the UK, the rate of schizophrenia in immigrant groups appears to vary with ethnicity ${ }^{4,5}$ but this replicated finding continues to court enormous controversy, particularly as the phenomenon is confused with, rather than confounded by, the important issue of institutional racism in health services. ${ }^{6}$ Black Caribbean and Black African groups in the UK have consistently been observed to have the highest incidence of psychoses, with conservative estimates suggesting a risk between four- and sixfold that of the White British population. The incidence of psychoses faced by other Black and minority ethnic (BME) groups also appears significantly elevated, but to a lesser magnitude. ${ }^{5,7,8}$ Elevated rates of psychoses among BME groups cannot be attributed to diagnostic bias, a predisposition for prodromal individuals to migrate (especially since rates remain elevated in so-called second-generation immigrants), higher rates in the immigrants' country of origin or confounding by age and gender. ${ }^{9}$ Socio-economic status may confound the association between immigration and psychoses, ${ }^{10}$ but this has yet to be tested in a UK setting or in a population-based first-episode study.

\section{Methods}

\section{Hypothesis}

We investigated the extent to which current socio-economic status confounded the association between ethnicity and the incidence of first-onset psychoses. Our null hypothesis was that the elevated incidence of psychoses across BME groups, compared with the White British group, would become non-significant after adjustment for current socio-economic status. We use the term 'Black and minority ethnic (BME) group ${ }^{\prime 11}$ to refer to any ethnic minority group, irrespective of place of birth: whether outside (first generation) or within (second or third generation) the UK.

Owing to the methodology of our study (described below) it was not possible to include a measure of parental socio-economic status at birth, which may have been more pertinent given the likely downward social drift of individuals in the prodromal phase of schizophrenia. We therefore acknowledge, from the outset, that our measure of current socio-economic status is likely to have misclassified individuals to a lower social class than they may have otherwise have achieved had they remained psychosis-free. Nevertheless, we have no reason to believe that this misclassification would have been differential across ethnic groups. Thus, any significant association we may observe between the incidence of psychotic disorder and BME status would be biased towards unity, making our results conservative, but providing evidence that elevated risk in these groups could not be entirely explained by socio-economic status.

\section{Study design}

We used data from the East London First-Episode Psychosis Study (ELFEP), a large population-based incidence study of first-episode psychoses, to test our hypothesis. The study was conducted over 2 years in three neighbouring London boroughs: City \& Hackney (December 1996 to November 1998), Newham (December 1998 to November 2000) and Tower Hamlets (December 1998 to November 2000). The area is exclusively inner-city urban, predominantly characterised by a large BME population, with high levels of immigration and socio-economic deprivation. The ELFEP methodology draws on the World Health Organization ten-country study ${ }^{12}$ and the UK three-centre Aetiology and Ethnicity in Schizophrenia and Other Psychosis (ÆSOP) study. ${ }^{1}$ Ethical approval was obtained from the local research ethics committee in East London. 


\section{Case ascertainment}

Everyone aged between 18 and 64 years living in the study area who made contact with mental health services because of a first episode of any probable psychosis, non-psychotic mania or bipolar disorder was identified. All potential cases presenting to psychiatric services for the first time were screened. Health service bases were contacted weekly to identify all potential candidates. Individuals with a likely organic basis to their disorder were excluded.

Individuals who passed the screen underwent a battery of assessments, including the Schedule for Clinical Assessment in Neuropsychiatry $(\mathrm{SCAN})^{13}$ and the Personal and Psychiatric History Schedule. ${ }^{13}$ The SCAN Item Group Checklist ${ }^{13}$ was completed for all individuals who declined an interview, based on case notes and information from clinical staff. The DSM$\mathrm{IV}^{14}$ diagnoses were allocated by consensus agreement between the clinical researcher who presented the clinical information and the principal investigator (J.W.C.) who remained masked to the ethnicity of the individual. We investigated four diagnostic categories: all clinically relevant psychoses, schizophrenia (DSMIV 295.xx), other non-affective psychoses (DSM-IV 297.xx, 298.8, 298.9) and affective psychoses (DSM-IV 296.x4, 296.4, 296.89).

A socio-demographic data schedule was administered to participants to obtain data on age, gender, ethnicity and occupation. Ethnicity was ascribed using all available information, including self-ascription, country of birth and country of parents' birth.

\section{Population at risk}

Denominator data were estimated for people aged 18-64 years, resident in the ELFEP study area at the time of the closest census (1 April 2001). Denominator data were commissioned from the Office for National Statistics (ONS) and stratified by age, gender, ethnicity and National Statistics Socio-Economic Classification (NS-SEC), ${ }^{15}$ an occupational-based classification included in the 2001 census to supersede previous socio-economic classifications (see below). Raw denominator data were multiplied by two to estimate person-years at risk over the 2-year study period.

\section{Statistical analyses}

\section{Variable coding}

Case and denominator data were stratified into five 10-year agebands (18-24, 25-34, 35-44, 45-54 and 55-64 years). Ethnicity was defined according to a 16-category variable used in the 2001 census. $^{11}$ From this, we created a collapsed 10-category ethnicity variable which included the following groups: White British, White Other, Mixed White and Black Caribbean, Mixed Other, Indian, Pakistani, Bangladeshi, Black Caribbean (including any African-American or other Black groups), Black African, and Other ethnic groups.

Socio-economic status was classified using the NS-SEC-5. ${ }^{15}$ This classification included seven occupational categories: managerial and professional, intermediate occupations, small account and own account workers, lower supervisory and technical occupations, semi-routine and routine occupations, never worked and long-term unemployed, and not classifiable. The not classifiable group included students, people with inadequately stated occupations or people unclassifiable for other reasons. Occupation data in ELFEP was recorded prior to the NS-SEC and cases were assigned an NS-SEC- 5 classification based on decision rules provided by the ONS. ${ }^{15}$

\section{Statistical methods}

We used Poisson regression to obtain incidence rate ratios (IRR) for the nine BME groups compared with the White British group after adjustment for age and gender. We then added NS-SEC-5 socio-economic status to our models to test our null hypothesis. We explored our hypothesis for our four diagnostic categories and for men and women separately if a statistically significant interaction between gender and ethnicity was observed. Modelling was conducted in Stata (Version 9) for Windows. The White British group, aged 18-24 years, women, and managerial and professional occupations provided the reference category for each variable. Statistical interactions and model fit were assessed via likelihood ratio test (LRT).

\section{Results}

Four hundred and eighty-four clinically relevant first-onset cases of psychoses were identified during 828546 person-years of follow-up (online Table DS1). Sixty-two per cent of these individuals were men, in contrast to $49 \%$ of the denominator population $(P<0.001)$. Individuals with psychoses were significantly younger $(P<0.001)$, more likely to come from a BME group $(P<0.001)$ and be of lower socio-economic status $(P<0.001)$ than the denominator population. Over half of those with psychoses received a DSM-IV diagnosis of schizophrenia (55.4\%; $n=268), 19 \%$ received a diagnosis of other non-affective psychoses $(n=94)$, with the remaining $25 \%$ being diagnosed with an affective psychosis $(n=122)$. Median age at onset for all clinically relevant psychoses was 27.5 years in men and 29.0 years in women (online Table DS1).

\section{All clinically relevant psychoses}

The risk of any psychoses was raised in nearly all BME groups compared with the White British group, after adjustment for age and gender (Adjustment 1, Table 1). Socio-economic status confounded some, but by no means all, of the excess risk for these groups (Adjustment 2, Table 1). Thus, after adjustment for age, gender and socio-economic status, the Black Caribbean (IRR=2.7, 95\% CI 2.0-3.7), Black African (IRR=2.5, 95\% CI 1.8-3.3), Mixed White and Black Caribbean (IRR=3.6, 95\% CI 2.0-6.6), and White Other (IRR=1.8, 95\% CI 1.3-2.4) groups remained at significantly elevated risk of psychoses. There was only a weak suggestion that the incidence of psychoses by ethnicity was modified by gender (LRT $P$-value for interaction $=0.07$ ).

\section{Schizophrenia}

Black Caribbean, Black African, Bangladeshi, and Mixed White and Black Caribbean groups had significantly raised rates of schizophrenia compared with the White British group after adjustment for age and gender (All cases, Adjustment 1, Table 2). Following additional adjustment for socio-economic status, only the Black Caribbean (IRR=3.1, 95\% CI 2.1-4.5) and Black African groups (IRR=2.6, 95\% CI 1.8-3.8) remained at significantly elevated risk (All cases, Adjustment 2, Table 2). However, there was evidence that the incidence of schizophrenia in BME groups differed by gender (LRT $P$-value for interaction=0.02). Thus, the pattern just described was observed for men (Men, Adjustment 2, Table 2). For women, significantly elevated IRR persisted after adjustment for socio-economic status in several ethnic groups, not limited to Black Caribbean (IRR=4.7, 95\% CI 2.3-9.7) and Black African groups (IRR=3.2, 95\% CI 1.5-6.8), but extending to the Mixed White and Black 
Table 1 Incidence rate ratios (IRR) of all clinically relevant DSM-IV psychoses in the East London First-Episode Psychosis Study population by ethnicity ${ }^{\mathrm{a}}$

\begin{tabular}{|c|c|c|c|}
\hline Ethnicity & Cases $(N=484), n(\%)$ & Adjustment $1^{\mathrm{b}} \mathrm{IRR}(95 \% \mathrm{Cl})$ & Adjustment $2^{\mathrm{C}}$ IRR $(95 \% \mathrm{Cl})$ \\
\hline White British & $112(23.1)$ & 1.0 & 1.0 \\
\hline White Other & $66(13.6)$ & $1.9(1.4-2.6)$ & $1.8(1.3-2.4)$ \\
\hline Black Caribbean & $78(16.1)$ & $4.0(3.0-5.4)$ & $2.7(2.0-3.7)$ \\
\hline Black African & $83(17.2)$ & $3.2(2.4-4.3)$ & $2.5(1.8-3.3)$ \\
\hline Indian & $26(5.4)$ & $1.4(0.9-2.2)$ & $1.1(0.7-1.7)$ \\
\hline Pakistani & $16(3.3)$ & $1.5(0.9-2.5)$ & $1.1(0.6-1.8)$ \\
\hline Bangladeshi & $64(13.2)$ & $1.7(1.3-2.4)$ & $1.0(0.7-1.3)$ \\
\hline Other ethnic group & $25(5.2)$ & $1.6(1.0-2.5)$ & $1.3(0.8-2.0)$ \\
\hline Mixed White and Black Caribbean & $12(2.5)$ & $5.5(3.0-9.9)$ & $3.6(2.0-6.6)$ \\
\hline Mixed Other & $2(0.4)$ & $0.4(0.1-1.4)$ & $0.3(0.1-1.1)$ \\
\hline
\end{tabular}

Caribbean population (IRR $=6.5,95 \%$ CI $1.8-22.8$ ) and Pakistani $\quad($ IRR $=3.1,95 \%$ CI 1.2-8.1) and Bangladeshi women (IRR=2.3, 95\% CI 1.1-4.7) (Women, Adjustment 2, Table 2).

\section{Other non-affective psychoses}

Several BME groups appeared to have a significantly higher incidence of other non-affective psychoses after adjustment for age and gender, compared with the White British group (Adjustment 1, Table 3). Socio-economic status could not explain all the excess risk; we observed significantly elevated IRR for Black Caribbean (IRR=2.2, 95\% CI 1.1-4.5), Black African（IRR=2.5, 95\% CI 1.3-4.9), and White Other groups (IRR=3.0, 95\% CI 1.6-5.5) (Adjustment 2, Table 3). There was no evidence that the incidence of psychoses by ethnicity was modified by gender (LRT $P$-value for interaction $=0.71$ ).

\section{Affective psychoses}

Elevated IRR for affective psychoses were observed in Black Caribbean, Black African, White Other, and Mixed White and Black Caribbean groups after adjustment for age and gender
(Adjustment 1, Table 4). These associations persisted after additional adjustment for socio-economic status. Thus, Black Caribbean $(\mathrm{IRR}=2.4,95 \%$ CI 1.3-4.3), Black African (IRR=2.1, 95\% CI 1.2-3.8) and White Other groups (IRR=2.1, 95\% CI 1.2-3.8) were at approximately twice the risk of an affective psychosis than the White British group. The rate of affective psychoses in the Mixed White and Black Caribbean group was particularly pronounced (IRR $=7.7,95 \%$ CI 3.2-18.8) (Adjustment 2, Table 4). There was no evidence that the incidence of affective psychoses by ethnicity differed between the genders (LRT $P$-value for interaction $=0.11$ ).

\section{Discussion}

\section{Principal findings}

This was the first epidemiological study of first-episode psychoses to simultaneously investigate the effects of age, gender and socioeconomic status across different ethnic groups in the UK. Although socio-economic status attenuated some risk of psychoses in BME groups, it was not sufficient to explain all the excess risk in certain BME groups. This finding was observed

\begin{tabular}{|c|c|c|c|c|c|c|c|c|c|}
\hline \multirow[b]{2}{*}{ Ethnicity } & \multicolumn{3}{|c|}{ All cases $(N=268)$} & \multicolumn{3}{|c|}{ Men $(N=177)$} & \multicolumn{3}{|c|}{ Women $(N=91)$} \\
\hline & $n(\%)$ & $\begin{array}{c}\text { Adjustment } 1^{\mathrm{b}} \\
\text { IRR } \\
(95 \% \mathrm{Cl})\end{array}$ & $\begin{array}{c}\text { Adjustment } 2^{c} \\
\text { IRR } \\
(95 \% \mathrm{Cl})\end{array}$ & $n(\%)$ & $\begin{array}{c}\text { Adjustment } 1^{d} \\
\text { IRR } \\
(95 \% \mathrm{Cl})\end{array}$ & $\begin{array}{c}\text { Adjustment } 2^{\mathrm{e}} \\
\text { IRR } \\
(95 \% \mathrm{Cl})\end{array}$ & $n(\%)$ & $\begin{array}{l}\text { Adjustment } 1^{d} \\
\text { IRR } \\
(95 \% \mathrm{Cl})\end{array}$ & $\begin{array}{c}\text { Adjustment } 2^{\mathrm{e}} \\
\text { IRR } \\
(95 \% \mathrm{Cl})\end{array}$ \\
\hline White British & $61(22.8)$ & 1.0 & 1.0 & $48(27.0)$ & 1.0 & 1.0 & $13(14.3)$ & 1.0 & 1.0 \\
\hline White Other & $26(9.7)$ & $1.4(0.9-2.2)$ & $1.2(0.8-2.0)$ & $16(9.1)$ & $1.1(0.6-1.9)$ & $1.0(0.6-1.8)$ & $10(11.0)$ & $2.3(1.0-5.3)$ & $2.1(0.9-4.8)$ \\
\hline Black Caribbean & $48(17.9)$ & $4.6(3.2-6.8)$ & $3.1(2.1-4.5)$ & $31(17.5)$ & $4.2(2.7-6.6)$ & $2.6(1.7-4.1)$ & $17(18.7)$ & $6.2(3.0-12.8)$ & $4.7(2.3-9.7)$ \\
\hline Black African & $48(17.9)$ & $3.4(2.3-5.0)$ & $2.6(1.8-3.8)$ & $33(18.7)$ & $3.2(2.0-4.9)$ & $2.5(1.6-3.9)$ & $15(16.4)$ & $4.4(2.1-9.4)$ & $3.2(1.5-6.8)$ \\
\hline Indian & $11(4.1)$ & $1.1(0.6-2.1)$ & $0.8(0.4-1.6)$ & $8(4.5)$ & $1.0(0.5-2.1)$ & $0.8(0.4-1.7)$ & $3(3.3)$ & $1.4(0.4-4.8)$ & $1.0(0.3-3.5)$ \\
\hline Pakistani & $11(4.1)$ & $1.7(0.9-3.3)$ & $1.3(0.7-2.4)$ & $5(2.8)$ & $1.0(0.4-2.4)$ & $0.8(0.3-1.9)$ & $6(6.6)$ & $4.9(1.9-13.0)$ & $3.1(1.2-8.1)$ \\
\hline Bangladeshi & $45(16.8)$ & $2.1(1.4-3.1)$ & $1.1(0.8-1.7)$ & $24(13.6)$ & $1.4(0.9-2.4)$ & $0.8(0.5-1.3)$ & $21(23.1)$ & $4.4(2.2-8.9)$ & $2.3(1.1-4.7)$ \\
\hline Other ethnic group & $12(4.5)$ & $1.4(0.7-2.6)$ & $1.1(0.6-2.1)$ & $11(6.2)$ & $1.6(0.8-3.0)$ & $1.3(0.7-2.4)$ & $1(1.1)$ & $0.5(0.1-4.2)$ & $0.5(0.1-3.5)$ \\
\hline $\begin{array}{l}\text { Mixed White and } \\
\text { Black Caribbean }\end{array}$ & $4(1.5)$ & $3.2(1.2-8.7)$ & $2.0(0.7-5.6)$ & $1(0.6)$ & $1.1(0.2-7.9)$ & $0.7(0.1-4.9)$ & $3(3.3)$ & $9.6(2.7-33.9)$ & $6.5(1.8-22.8)$ \\
\hline Mixed Other & $2(0.7)$ & $0.6(0.2-2.6)$ & $0.5(0.1-2.0)$ & 0 & - & - & $2(2.2)$ & $2.8(0.6-12.3)$ & $2.1(0.5-9.3)$ \\
\hline
\end{tabular}


Table 3 Incidence rate ratios (IRR) of DSM-IV other non-affective psychoses in the East London First-Episode Psychosis Study by ethnicity ${ }^{\mathrm{a}}$

\begin{tabular}{|c|c|c|c|}
\hline Ethnicity & Cases $(N=94), n(\%)$ & Adjustment $1^{\mathrm{b}}$ IRR $(95 \% \mathrm{Cl})$ & Adjustment $2^{\mathrm{C}}$ IRR (95\% Cl) \\
\hline White British & $21(22.3)$ & 1.0 & 1.0 \\
\hline White Other & $20(21.3)$ & $3.2(1.7-5.9)$ & $3.0(1.6-5.5)$ \\
\hline Black Caribbean & $12(12.8)$ & $3.2(1.6-6.6)$ & $2.2(1.1-4.5)$ \\
\hline Black African & $16(17.0)$ & $3.3(1.7-6.4)$ & $2.5(1.3-4.9)$ \\
\hline Indian & $9(9.6)$ & $2.7(1.2-5.9)$ & $2.0(0.9-4.2)$ \\
\hline Pakistani & 0 & - & - \\
\hline Bangladeshi & $8(8.5)$ & $1.2(0.5-2.8)$ & $0.7(0.3-1.6)$ \\
\hline Other ethnic group & $6(6.4)$ & $2.1(0.9-5.3)$ & $1.7(0.7-4.1)$ \\
\hline \multicolumn{4}{|c|}{ Mixed White and Black } \\
\hline Caribbean & $2(2.1)$ & $5.2(1.2-22.1)$ & $3.5(0.8-14.9)$ \\
\hline Mixed Other & 0 & - & - \\
\hline
\end{tabular}

across several diagnostic outcomes, raising the possibility that migration or post-migratory experiences are important in the aetiology of psychoses.

Black Caribbean and Black African groups were generally at least twice as likely to experience any psychotic disorder compared with their White British counterparts, after adjustment for age, gender and socio-economic status. We also demonstrated that the Mixed White and Black Caribbean group, who perhaps present a marker for so-called third-generation immigrants, appear to be at particularly elevated risk, notably for affective psychoses. Excess rates of other non-affective psychoses and affective psychoses persisted for the White Other group after adjustment for socioeconomic status. Perhaps most notably, we observed evidence that Pakistani and Bangladeshi women were at elevated risk of schizophrenia even after adjustment for socio-economic status.

\section{Methodological considerations}

It is salient to discuss whether we should have controlled for current socio-economic status in our models. Lower current socio-economic status is strongly associated with increased risk of psychoses; the most parsimonious explanation being the drift of premorbid individuals into lower social classes. ${ }^{10,16-18} \mathrm{We}$ recognise that use of current socio-economic status will have inevitably misclassified individuals who experienced downward social drift as a result of the onset of the prodromal phase of the disorder. However, all previous UK studies demonstrating raised rates of psychoses among BME groups adjusted only for age and gender. We believed that further replication of this wellestablished finding would have been of little empirical value. Parental socio-economic status at birth of the individual would have provided a better confounder of the relationship between ethnicity and psychoses, but this variable is not routinely collected for the denominator population at risk in the UK. We therefore chose to control for current socio-economic status, acknowledging its limitations over parental socio-economic status at birth of the individual, in order to answer calls to address this controversial issue. ${ }^{6,10}$ We have separated the respective roles of ethnicity and socio-economic status with respect to the risk of psychoses in the UK. Our decision to use current socio-economic status may have led to an overestimation of the true effect of socio-economic status (given social drift), meaning that our estimates of elevated risk of psychoses among BME groups are likely to be conservative. We have no reason to believe that social drift would have operated differentially across ethnic groups.

The NS-SEC may not have measured socio-economic status perfectly, making it impossible to exclude residual confounding as an explanation of our findings. We attempted to minimise this by using the broadest NS-SEC categorisation available for our analyses (NS-SEC-5).

We used a prospective, case-finding design, with standardised diagnoses made masked to the ethnicity of the individual, to

Table 4 Incidence rate ratios (IRR) of DSM-IV affective psychoses in the East London First-Episode Psychosis Study by ethnicity ${ }^{\mathrm{a}}$

\begin{tabular}{|c|c|c|c|}
\hline Ethnicity & Cases $(N=122), n(\%)$ & Adjustment $1^{\mathrm{b}} \mathrm{IRR}(95 \% \mathrm{Cl})$ & Adjustment $2^{\mathrm{C}}$ IRR $(95 \% \mathrm{Cl})$ \\
\hline White British & $30(24.6)$ & 1.0 & 1.0 \\
\hline White Other & $20(16.4)$ & $2.3(1.3-4.0)$ & $2.1(1.2-3.8)$ \\
\hline Black Caribbean & $18(14.8)$ & $3.3(1.9-6.0)$ & $2.4(1.3-4.3)$ \\
\hline Black African & $19(15.6)$ & $2.7(1.5-4.9)$ & $2.1(1.2-3.8)$ \\
\hline Indian & $6(4.9)$ & $1.3(0.5-3.0)$ & $1.0(0.4-2.3)$ \\
\hline Pakistani & $5(4.1)$ & $1.8(0.7-4.7)$ & $1.4(0.5-3.5)$ \\
\hline Bangladeshi & $11(9.0)$ & $1.2(0.6-2.4)$ & $0.7(0.3-1.4)$ \\
\hline Other ethnic group & $7(5.7)$ & $1.7(0.8-4.0)$ & $1.4(0.6-3.2)$ \\
\hline \multicolumn{4}{|c|}{ Mixed White and Black } \\
\hline Caribbean & $6(4.9)$ & $10.9(4.5-26.3)$ & $7.7(3.2-18.8)$ \\
\hline Mixed Other & 0 & - & - \\
\hline
\end{tabular}


estimate incidence rate ratios for psychoses across several BME groups in a single centre. This study was based on two methodologically robust studies. ${ }^{1,12}$ We considered several immigrant groups, stratified by ethnicity. Ethnicity was ascribed by a researcher with experience in research in ethnic minorities (J.W.C.). We acknowledge the potential for individuals with psychosis to misclassify themselves as of mixed ethnicity (reverse causality), although we believe this unlikely given that self-ascription was used in conjunction with other data used to ascribe ethnicity.

We were unable to adjust for family history of psychiatric disorder because such data were unavailable for our denominator. A previous study found that the relationship between parental socio-economic status and schizophrenia was not significantly confounded by family history of psychiatric disorder. ${ }^{17}$

We used the 2001 census to estimate the denominator population, which avoided under-enumeration of BME groups, men and younger people through its 'one number' methodology. Using two different case ascertainment periods may have invited some error into the results, particularly as our denominators were estimated from the same source. However, applying corrections based on estimates from the previous 1991 census would only have invited further error.

It will be important to disentangle the respective roles of immigration and ethnic minority status. Here, we have been careful to discuss the effects of ethnicity alone, and we have not considered the correlated effect of generation status (for example, first- $v$. second-generation immigrants). Our sample does show variation by generation status, given differential migration histories to the UK associated with various BME groups. For example, $80 \%$ of our Black Caribbean sample were secondgeneration immigrants or later, reflecting the fact that the majority of first-generation immigrants from these groups, who predominantly migrated during the 1950s and 1960s, are now passed the main age period of risk for psychoses. For other groups though, such as Black African, White Other or Bangladeshi groups, this pattern was reversed, with the overwhelming majority of the sample, and denominator, being first-generation immigrants. It was not possible to investigate simultaneously the effects of age, gender, ethnicity, socio-economic status and generation status in this paper since denominator data were not available from the ONS to this degree of fidelity, owing to potential disclosure issues. Separating out the competing issues of immigration and ethnicity remains an important challenge, particularly as the UK is witnessing an unprecedented level of immigration from Eastern Europe following expansion of the European Union (EU).

\section{Comparison with other studies}

We have replicated significantly elevated risk of psychoses in BME groups observed recently in another part of inner London, ${ }^{5}$ and like that study, confirmed considerable heterogeneity by ethnicity and gender. The IRR reported here, particularly for Black Caribbean and Black African groups, were lower than in the ÆSOP study, but were none the less comparable. Taken together, these studies have surveyed over $40 \%$ of London's inner-city boroughs, making our findings of considerable use to mental healthcare service providers.

Our study area had a large Asian population, which gave us sufficient power to obtain robust IRR for Indian, Pakistani and Bangladeshi groups independently. For example, we had $82 \%$ power to detect an IRR of at least two for the risk of schizophrenia in the Bangladeshi group (full power analyses available from authors). Previous studies have considered these populations as a homogeneous group, ${ }^{7,8}$ thus giving conflicting findings that have been of little benefit to understanding psychoses in these groups. ${ }^{19}$

It is important to note that we have observed raised rates of other non-affective psychoses and affective psychoses in the White Other group. This replicates a similar finding from the ÆSOP study. ${ }^{5}$ In addition, raised rates of schizophrenia have been observed in Finnish immigrants to Sweden, ${ }^{20}$ Australian and Greenlandic immigrants to Denmark, ${ }^{21}$ and German and Polish immigrants to Australia. ${ }^{3}$ Despite heterogeneity by disorder, ethnicity, generation status and gender, taken together these studies serve as an important reminder that factors associated with minority status are likely to confer an increased risk of psychoses irrespective of ethnicity, race or colour.

\section{Meanings of the findings}

The epidemiological evidence now persuasively argues that the tenet that schizophrenia and other psychoses occur equally between peoples and places is unsustainable. ${ }^{1,3}$ Our study extends the UK literature by demonstrating that elevated rates of psychoses among BME groups are unlikely to be entirely confounded by socio-economic status, despite the limitations of our measure. Elevated rates of schizophrenia were not confined to Black Caribbean or Black African groups, but persisted among Pakistani and Bangladeshi women. After controlling for current socio-economic status, schizophrenia was ubiquitously raised in these groups: between two- and threefold that of the White British group. This finding runs counter to the prevailing axiom. ${ }^{22}$ Mixed White and Black Caribbean and White Other groups were at significantly elevated risk of affective psychoses, even after adjustment for socio-economic status. These novel findings will need to be incorporated into future hypotheses, ${ }^{6}$ study designs and healthcare provision, as our focus shifts towards preventive models of psychoses.

Increasingly robust epidemiological designs make misdiagnosis an unlikely explanation for raised rates in BME groups, ${ }^{5}$ particularly when taken with the broad definition of psychotic disorder used here. Higher rates in the immigrants' country of origin have also been excluded as an alternative explanation. ${ }^{23-25}$ Raised rates in second-generation immigrants in the $\mathrm{UK}^{26}$ and elsewhere in Europe, ${ }^{27}$ suggest that schizophrenia is unlikely to predispose individuals to migrate. Given the complexity surrounding the task of migration, this explanation would also appear unlikely. ${ }^{28}$

Our findings complement a previous study of all people with schizophrenia admitted to hospital in Sweden over a 10-year period. ${ }^{29}$ Hjern et al ${ }^{29}$ observed that despite attenuation in the incidence of schizophrenia in immigrants following adjustment for parental socio-economic status, elevated risk remained, a finding recently replicated in a separate study adjusting for current socio-economic status. ${ }^{20}$ Furthermore, Byrne et al ${ }^{17}$ investigated the role of parental socio-economic status and psychoses in a Danish cohort, finding 'little evidence that family [parental] socio-economic status was consistently associated with increased risk of schizophrenia. This does not, however, preclude markers of childhood adversity as being important in the risk of later psychoses. A recent study by the $Æ S O P$ group found that aberrant childhood separation from parents was associated with an increased risk of schizophrenia independently for the White British, Black Caribbean and Black African groups. ${ }^{30}$ Such separation events were more prevalent in the Black Caribbean group, suggesting that this may provide a marker for a degree of underlying disadvantage experienced by this group that may contribute to their excess risk of psychoses. 
We considered socio-economic status to be a potential confounder in the association between ethnicity and the risk of psychoses. In doing so, we assumed that socio-economic status is a marker for underlying social adversity of some kind relevant to the aetiology of psychoses. Although we found that current socio-economic status did partially confound this relationship it was not sufficient to explain the majority of the risk of psychoses in BME groups. Further, although lower current socio-economic status was strongly associated with higher incidence rates of psychoses (data available from authors), this is not surprising given social drift. These findings suggest that socio-economic status may not be a good marker for social adversity. Other measures of social adversity, at both the individual ${ }^{30}$ and neighbourhood level, ${ }^{28,31,32}$ have been associated with an increased risk of psychoses, although it will be important to test whether experiences of social adversity differ according to ethnicity and immigration.

We suggest that migratory or post-migratory experiences present a set of risk factors to explain raised rates of psychoses among BME groups. A recent study in The Hague found an association between perceived discrimination and increased incidence of schizophrenia among immigrants. ${ }^{33}$ The raised rates of psychoses we observed for the Mixed White and Black Caribbean group suggest that elevated risk may extend into third-generation immigrants. This group may be exposed to continued discrimination, despite their British citizenship, contributing to their stress burden. Equally, this group is a diverse, emerging ethnic group, and it is possible that stressors associated with forging new cultural identities, perhaps neither wholly British nor Caribbean, contribute to the onset of psychotic symptoms in this group. The heterogeneity in risk across BME groups suggests that although factors such as social adversity or discrimination may apply generally across minority groups, ethnic-specific factors (such as resilience or socio-cultural support) must also operate in the aetiology of psychoses.

The stress-vulnerability model presents a putative mechanism for raised rates among BME groups, including the Mixed White and Black Caribbean group, although individual risk may be mediated through genetic susceptibility. ${ }^{34}$ Through chronic exposure to social stress, ${ }^{35}$ it is possible that the dopamine system, implicated in the pathogenesis of psychosis, could become dysregulated to such an extent that eventually manifests in positive psychotic symptoms and subsequent onset of psychoses. ${ }^{36}$ This pathway is likely to be complex, influenced by major life events at critical periods across the life course, genetic susceptibility and contextual, neighbourhood-level socio-environmental risk factors. In support of this, Weiser et $a l^{37}$ found that the incidence of schizophrenia increased with population density, but that this effect was nine times greater for people with a pre-existing vulnerability to psychoses, expressed as poor premorbid social and cognitive functioning, than in those without.

The risk of schizophrenia appears to be greater for BME individuals in neighbourhoods with lower proportions of BME residents. $^{38}$ Neighbourhood-level social adversity $^{29}$ or fragmentation ${ }^{39}$ are also associated with the incidence of schizophrenia, independent of socio-economic status, ${ }^{32}$ but this finding has yet to be tested across ethnic groups. Our findings for the affective psychoses are interesting given that elevated rates persisted for some BME groups after controlling for socio-economic status, but that the affective psychoses apparently show no variation at the neighbourhood level. ${ }^{40}$ Putative socioenvironmental risk factors, potentially operating at other levels such as the individual or family level - including childhood aberrant separation ${ }^{30}$ or stressful life events, ${ }^{41}$ may be more aetiologically relevant to the affective psychoses than factors at the neighbourhood level.

\section{Future challenges}

On 1 January 2007 Romania and Bulgaria became the 26th and 27 th member states of the EU. New possibilities to migrate are transforming the social, economic and political landscape of EU member states, including the UK. The expansion of the EU since May 2004 has led to an unprecedented rise in migration, with many Western European countries, including the UK, becoming net recipients of large numbers of economic migrants. Between 2003 and 2004, for example, net immigration to the UK rose by nearly $50 \%$, increasing the population by $223000 .{ }^{42}$ Given the increased rates of psychoses among non-British White migrants (see our results and Fearon $e t a l^{5}$ ), current UK immigration patterns may present substantial challenges for mental healthcare services in the forthcoming decade. We need to prepare for the prospect of psychiatric morbidity in these groups, ensure that our services are sensitive to their needs and continue to research a phenomenon that not only results in suffering and disability, but may also be a window on the causes of psychotic disorders more generally.

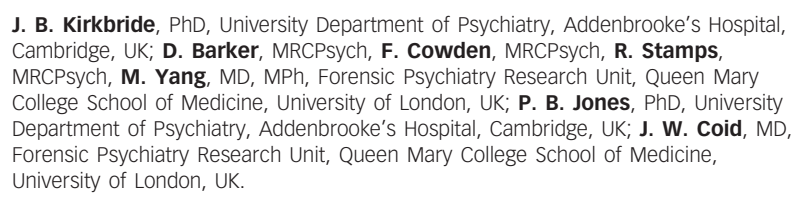

J. B. Kirkbride, PhD, University Department of Psychiatry, Addenbrooke's Hospital, Cambridge, UK; D. Barker, MRCPsych, F. Cowden, MRCPsych, R. Stamps, MRCPsych, M. Yang, MD, MPh, Forensic Psychiatry Research Unit, Queen Mary College School of Medicine, University of London, UK; P. B. Jones, PhD, University Department of Psychiatry, Addenbrooke's Hospital, Cambridge, UK; J. W. Coid, MD, Forensic Psychiatry Research Unit, Queen Mary College School of Medicine, University of London, UK.

Correspondence: J. B. Kirkbride, Box 189, University Department of Psychiatry, Addenbrooke's Hospital, Hills Road, Cambridge CB2 2QQ, UK. Email: jbk25@cam.ac.uk

First received 14 Jun 2007, final revision 25 Jan 2008, accepted 4 Feb 2008

\section{Acknowledgements}

We wish to acknowledge the ASSOP study team for help and advice on the design of the study. J.W.C. and J.B.K. had full access to the data and agree to take responsibility for the integrity of the data and the accuracy of the data analysis. This study was funded by grants from St Bartholomew's \& the Royal London Hospital Special Trustees and East London \& the City Mental Health NHS Trust R\&D. The funding bodies were not involved in the design and conduct of the study; collection, management, analysis and interpretation of the data; or preparation, review or approval of the manuscript. All researchers had complete independence from funders.

\section{References}

1 Kirkbride JB, Fearon P, Morgan C, Dazzan P, Morgan K,Tarrant J, Lloyd T, Holloway J, Hutchinson G, Leff JP, Mallett RM, Harrison GL, Murray RM, Jones PB. Heterogeneity in incidence rates of schizophrenia and other psychotic syndromes: findings from the 3-center AESOP Study. Arch Gen Psychiatry 2006; 63: 250-8.

2 Ödegaard O. Emigration and insanity. Acta Psychiatr Neurol 1932 (suppl 4): 1-206.

3 Cantor-Graae E, Selten J-P. Schizophrenia and migration: a meta-analysis and review. Am J Psychiatry 2005; 162: 12-24.

4 Harrison G, Owens D, Holton A, Neilson D, Boot D. A prospective study of severe mental disorder in Afro-Caribbean patients. Psychol Med 1988; 18: 643-57.

5 Fearon P, Kirkbride JB, Morgan C, Dazzan P, Morgan K, Lloyd T, Hutchinson G, Tarrant J, Fung WL, Holloway J, Mallett R, Harrison G, Leff J, Jones PB, Murray RM. Incidence of schizophrenia and other psychoses in ethnic minority groups: results from the MRC AESOP Study. Psychol Med 2006; 36 1541-50.

6 Singh SP, Burns T. Race and mental health: there is more to race than racism. BMJ 2006; 333: 648-51.

7 Bhugra D, Leff J, Mallett R, Der G, Corridan B, Rudge S. Incidence and outcome of schizophrenia in Whites, African-Caribbeans and Asians in London. Psychol Med 1997; 27: 791-8. 
8 King $M$, Coker E, Leavey G, Hoare A, Johnson-Sabine E. Incidence of psychotic illness in London: comparison of ethnic groups. BMJ 1994; 309: $1115-9$

9 Sharpley M, Hutchinson G, McKenzie K, Murray RM. Understanding the excess of psychosis among the African-Caribbean population in England Review of current hypotheses. Br J Psychiatry 2001; 178 (suppl 40): S60-8.

10 Cooper B. Immigration and schizophrenia: the social causation hypothesis revisited. Br J Psychiatry 2005; 186: 361-3.

11 National Institute for Mental Health in England. Inside Outside: Improving Mental Health Services for Black and Minority Ethnic Communities in England. Department of Health, 2003.

12 Jablensky A, Sartorius N, Ernberg G, Anker M, Korten A, Cooper JE, Day R, Bertelsen A. Schizophrenia: manifestations, incidence and course in different cultures. A World Health Organization ten-country study. Psychol Med Monogr Suppl 1992; 20: 1-97.

13 World Health Organization. Schedule for Clinical Assessment in Neuropsychiatry. WHO, 1992

14 American Psychiatric Assocation. Diagnostic and Statistical Manual of Mental Disorder (4th edn) (DSM-IV). APA, 1994

15 office for National Statistics. The National Statistics Socio-economic Classification User Manual. 2005 (http://www.statistics.gov.uk/ methods_quality/ns_sec/).

16 Jones PB, Bebbington P, Foerster A, Lewis SW, Murray RM, Russell A, Sham $\mathrm{PC}$, Toone BK, Wilkins S. Premorbid social underachievement in schizophrenia. Results from the Camberwell Collaborative Psychosis Study. Br J Psychiatry 1993; 162: 65-71.

17 Byrne M, Agerbo E, Eaton WW, Mortensen PB. Parental socio-economic status and risk of first admission with schizophrenia - a Danish national register based study. Soc Psychiatry Psychiatr Epidemiol 2004; 39: 87-96.

18 Goldberg EM, Morrison SL. Schizophrenia and social class. Br J Psychiatry 1963; 109: 785-802.

19 Bhopal RS, Phillimore P, Kohli HS. Inappropriate use of the term 'Asian': an obstacle to ethnicity and health research. J Public Health Med 1991; 13: 244-6.

20 Leao TS, Sundquist J, Frank G, Johansson LM, Johansson SE, Sundquist K. Incidence of schizophrenia or other psychoses in first- and secondgeneration immigrants: a national cohort study. J Nerv Ment Dis 2006; 194 27-33.

21 Cantor-Graae E, Pedersen CB, MCNeil TF, Mortensen PB. Migration as a risk factor for schizophrenia: a Danish population-based cohort study. $\mathrm{Br} \mathrm{J}$ Psychiatry 2003; 182: 117-22.

22 Fearon $\mathrm{P}$, Morgan $\mathrm{C}$. Environmental factors in schizophrenia: the role of migrant studies. Schizophr Bull 2006; 32: 405-8.

23 Bhugra D, Hilwig M, Hossein B, Marceau H, Neehall J, Leff J, Mallett R, Der G. First-contact incidence rates of schizophrenia in Trinidad and one-year follow-up. Br J Psychiatry 1996; 169: 587-92.

24 Hickling FW, Rodgers-Johnson P. The incidence of first contact schizophrenia in Jamaica. Br J Psychiatry 1995; 167: 193-6.

25 Mahy GE, Mallett R, Leff J, Bhugra D. First-contact incidence rate of schizophrenia on Barbados. Br J Psychiatry 1999; 175: 28-33.
26 Harrison G, Brewin J, Cantwell R, Dalkin T, Fox R, Medley I, Walder C. The increased risk of psychosis in African-Caribbean migrants to the UK: a replication. Schizophr Res 1996; 18: 102.

27 Veling W, Selten JP, Veen N, Laan W, Blom JD, Hoek HW. Incidence of schizophrenia among ethnic minorities in the Netherlands: a four-year firstcontact study. Schizophr Res 2006; 86: 189-93.

28 Lundberg $\mathrm{P}$, Cantor-Graae $\mathrm{E}$, Kahima M, Ostergren PO. Delusional ideation and manic symptoms in potential future emigrants in Uganda. Psychol Med 2007; 37: 505-12.

29 Hjern A, Wicks S, Dalman C. Social adversity contributes to high morbidity in psychoses in immigrants - a national cohort study of two generations of Swedish residents. Psychol Med 2004; 34: 1025-33.

30 Morgan C, Kirkbride JB, Leff J, Craig T, Hutchinson G, McKenzie K, Morgan K, Dazzan P, Doody GA, Jones P, Murray R, Fearon P. Parental separation, loss and psychosis in different ethnic groups: a case-control study. Psychol Med 2007; 37: 495-503.

31 Kirkbride JB, Morgan C, Fearon P, Dazzan P, Murray RM, Jones PB. Neighbourhood-level effects on psychoses: re-examining the role of context. Psychol Med 2007; 37: 1413-25.

32 Silver E, Mulvey EP, Swanson JW. Neighborhood structural characteristics and mental disorder: Faris and Dunham revisited. Soc Sci Med 2002; 55: 1457-70.

33 Veling W, Selten J-P, Susser E, Laan W, Mackenbach JP, Hoek HW Discrimination and the incidence of psychotic disorders among ethnic minorities in The Netherlands. Int J Epidemiol 2007; 36: 761-8.

34 Zubin J, Spring B. Vulnerability - a new view of schizophrenia. J Abnorm Psychol 1977; 86: 103-26.

35 Selten JP, Cantor-Graae E. Social defeat: risk factor for schizophrenia? Br J Psychiatry 2005; 187: 101-2.

36 Garety PA, Kuipers E, Fowler D, Freeman D, Bebbington PE. A cognitive model of the positive symptoms of psychosis. Psychol Med 2001; 31:189-95.

37 Weiser M, van Os J, Reichenberg A, Rabinowitz J, Nahon D, Kravitz E, Lubin G, Shmushkevitz M, Knobler HY, Noy S, Davidson M. Social and cognitive functioning, urbanicity and risk for schizophrenia. Br J Psychiatry 2007; 191: $320-4$.

38 Boydell J, van Os J, McKenzie K, Allardyce J, Goel R, Mccreadie RG, Murray RM. Incidence of schizophrenia in ethnic minorities in London: ecological study into interactions with environment. BMJ 2001; 323: 1336-8.

39 Allardyce J, Gilmour H, Atkinson J, Rapson T, Bishop J, McCreadie RG. Social fragmentation, deprivation and urbanicity: relation to first-admission rates for psychoses. Br J Psychiatry 2005; 187: 401-6.

40 Kirkbride JB, Fearon P, Morgan C, Dazzan P, Morgan K, Murray RM, Jones PB. Neighbourhood variation in the incidence of psychotic disorders in Southeast London. Soc Psychiatry Psychiatr Epidemiol 2007; 42: 438-45.

41 Norman RM, Malla AK. Stressful life events and schizophrenia. I: a review of the research. Br J Psychiatry 1993; 162: 161-6.

42 Office for National Statistics. International Migration (http:// www.statistics.gov.uk/cci/nugget.asp?id=1311). 